\title{
Pharmaceutical study of guduchi satva using the advanced technology-multi mill
}

\begin{abstract}
Guduchi (Tinospora cordifolia Linn) is one of the widely used herbs for therapeutic purpose. Satva (active part) is the dosage form Guduchi which is effective in fewer doses also. But various practical obstacles are seen while preparing Guduchi satva by conventional method described in the classical texts. In present study, for the preparation of Guduchi satva, use of a modern instrument named Multi mill has been done. It has been proved beneficial and economical too. Use of Multi mill is found hygienic, also yield of Satva is found to be more by using the Multi mill as compared to the conventional method.
\end{abstract}

Keywords: satva, conventional method, multi mill, hygienic
Volume 7 Issue 2 - 2017

\author{
PallaviV Bhange, Yogesh S Bhatambre, Pankaj \\ $\checkmark$ Bhange \\ Department of Rasashastra and Bhaishajya Kalpana, MAM's \\ Sumatibhai Shah Ayurved Mahavidyalaya, India
}

Correspondence: Pallavi V Bhange, Department of Rasashastra and BK, MAM's SSAM, Hadapsar Pune, Maharashtra, India, Tel 9822745774, Email pybhatambre@gmail.com

Received: March 30, 2017| Published: May 24, 2017

\section{Introduction}

Satva means the essence or active part. It refers to the starchy material of that plant, extractable in water. Satva can be obtained from the plants containing starch in more quantity. Guduchi (Tinospora cordifolia Linn) is an Ayurvedic herb, being widely used for therapeutic applications. It is referred as 'Indian Quinine' as it is effective in febrile conditions. ${ }^{1}$ Satva obtained from Guduchi is indicated in Daha (burning sensation) and Pittaj roga (Pitta predominant disorders). In Yog Ratnakar, while describing Guduchydi Modak, method of preparation of Guduchi Satva has been described as follows. Thumb sized stems of Guduchi are collected. These are cut into small pieces and outer husk is removed. Then these are crushed properly and soaked in sufficient quantity of water for 6-8hours. After soaking the stems, it is macerated well in the water. When the macerated stems lose all its mucilaginous content in water, it is filtered. Thus the fibrous and other course materials are removed. Then the filtrate is kept aside undisturbed to allow the Satva to settle down. The water is then siphoned off without disturbing the sediment. The sediment i.e. Satva is collected and dried. Satva obtained is Shankhanibha i.e. White in color. ${ }^{2}$

Another reference regarding Satva is found as follows. Thumb sized stems of Guduchi are collected. These are cut into small pieces, washed well and then crushed. Four parts of water are added to these pieces. The pieces are then macerated/ rubbed manually in the water. Then the mixture is filtered through a clean cloth and the filtrate is kept aside for whole night. Next day, the water above is removed by siphon method. Satva settled at the bottom of the container is collected. ${ }^{3}$

\section{Practical obstacles in the conventional method}

When Guduchi Satva is prepared as per above reference, following practical obstacles are seen. When Satva has to be prepared on large scale (commercial), utensils having large capacity are required. Cutting of large amount of Guduchi stems into small pieces becomes quite tedious. Crushing the stems manually becomes more tedious. Yield of Satva is very less i.e. only 0.4 to $2 \%$ yield is there when Guduchi stems are crushed manually. It is convenient for preparing the Satva in fewer amounts. But as mentioned above, it becomes very difficult and tedious job for large scale production of Guduchi Satva. With the advancements in the technologies, various advance instruments have been developed in the area of manufacturing. While observing the steps to be followed during preparation of Satva, the instrument Multi Mill has been thought to be helpful. Multi Mill, as its name indicates, is useful for dry as well as wet grinding e.g. for the preparation of Swarasa, Kalka, Choorna, etc. While preparing Guduchi Satva, the process of crushing the stems could be done easily using this machine. It can serve better crushing and thus can provide maximum yield of Guduchi Satva. Present study was done by two different methods. In first method, the conventional method of preparing Satva was followed i.e. crushing of Guduchi stems was done manually and the Satva obtained was observed and weighed. For the second method, Multi mill was used for crushing the Guduchi stems. The methodology is described as follows.

\section{Materials and method}

\section{Method I: Preparation of guduchi satva manually (Figure I)}

Raw material: Fresh Guduchi stems having medium size $(1.6-2.0 \mathrm{~cm}$ diameter)-10kg.

Procedure: Guduchi stems were chopped into pieces of 1.5 to 2 inches size. These were then washed well and then pounded thoroughly into coarse slimy mass. To these crushed stems, 4 parts of water was added. Stems were macerated well manually in the water. The mixture was then filtered through a clean cloth and the filtrate was kept aside whole night. Next day, the supernatant water was removed by siphon method. Satva settled at the bottom of the container was collected and dried.

\section{Observations}

a. Time period- Time required to one Person for cutting and crushing/pounding the $10 \mathrm{~kg}$ Guduchi stems manually 4 hrs.

\section{b. Satva Color- White}

c. Taste-Slightly Bitter

d. Weight - 200gm

Method II: Preparation of guduchi satva using multi Mill (GMP model) (Figure 2)

Raw material: Fresh Guduchi stems having medium size (1.6-2.0 cm diameter)-10kg. 
Procedure: Guduchi stems were chopped as described in Method I. The Multi Mill was run and these stems were then subjected to the hopper of the Multi Mill little by little. Pre measured four times water was also added as required to these stems while crushing. The stems were well crushed. The output material was containing the crushed stems along with water. The crushed stem material was collected. The mixture was then filtered through a clean cloth and the filtrate was kept aside whole night. Next day, the Satva, which was settled at the bottom of the container, was obtained similarly by siphon method as described in method I.

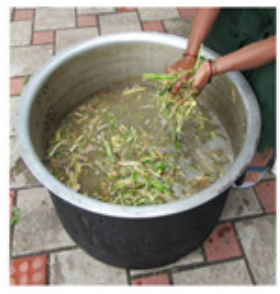

(A)

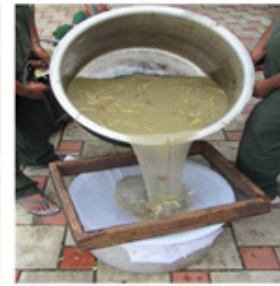

(B)

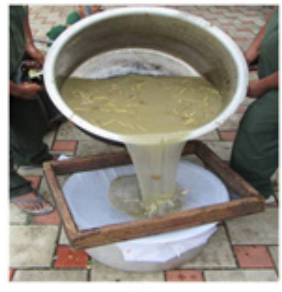

(c)
Figure I Preparation of Guduchi Satva by Conventional method.

A. Crushing of the Guduchi stems manually

B. Filtration of the crushed mixture

C. Sedimented satva

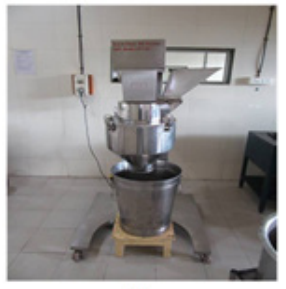

(A)

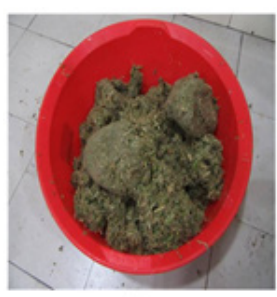

(D)

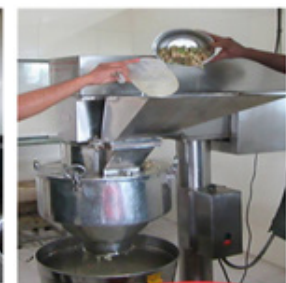

(B)

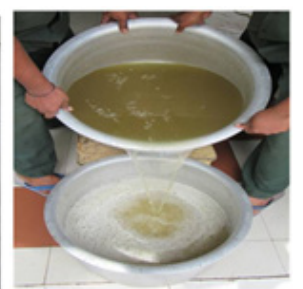

(E)

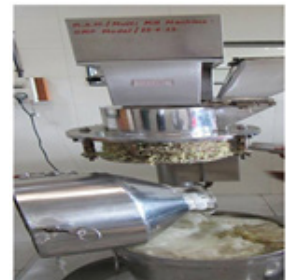

(c)

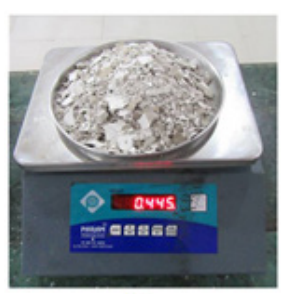

(F)
Figure 2 Preparation of Guduchi Satva using Multi Mill.
A. Multi Mill
B. Pouring chopped stems along with water to the Multi Mill
C. Crushed Guduchi Stems
D. Separated Guduchi Fibres
E. Decantation of water
F. Obtained Guduchi Satva

\section{Observations}

a. Time Period-Time required to one Person for cutting and crushing 10kg Guduchi Stems using Multi Mill 2 hrs

b. Satva Color-White

c. Taste-Slightly Bitter

d. Weight- $445 \mathrm{gm}$

\section{Result}

a. In method II, time required for cutting and crushing the stems using Multi Mill is found very less as compared to that for method I.

b. In method II, hygiene was also maintained as the crushing of the stems was done by the compact instrument i.e. Multi Mill GMP model.

c. The crushed material obtained from Method II was more uniform as compared to that from method I.

d. Yield of Satva from method II i. e. using Multi mill is more as compared to that from method I.

e. Yield:

I. Method I: 2 \% i.e. $200 \mathrm{gm}$ satva from $10 \mathrm{~kg}$ fresh Guduchi

II. Method II: $4.45 \%$ i.e. 445 gm satva from $10 \mathrm{~kg}$ fresh Guduchi

Thus, without disturbing the principle of classical method, Guduchi Satva can be obtained using the modern technology i.e. Multi mill with the benefits of acquiring more yields in hygienic condition.

\section{Discussion}

Previous studies show the preparation of Guduchi Satva using varieties of Guduchi plant, using different sizes of the Guduchi stem, using fresh and dried stem, using male and female Guduchi, etc. These studies have compared the yield of Satva accordingly. Rao et al., ${ }^{4}$ reported yield of $0.48 \%$ Satva from fresh stem and $1.20 \%$ from dried stem of Guduchi. Salunke et al., ${ }^{5}$ reported extraction of 0.15 $\%$ of Satva from fresh stem. In the study on Guduchi Satva extracted from different stem sizes of Guduchi, Sharma obtained maximum yield of Satva (2.7\%) from medium sized $(1.6-2.0 \mathrm{~cm})$ fresh stems. ${ }^{6}$ In the study of physicochemical evaluation of Satva extracted from male and female plants of Guduchi, yield of Satva from male and female stem was $2.25 \%$ and $3.18 \%$ respectively. ${ }^{7}$ However, use of any modern technique/instrument for obtaining the yield in more quantity using less Manpower in hygienic conditions is not seen. From present study, use of Multi mill, a modern instrument, proves beneficial for getting the maximum yield of satva under hygienic conditions. Several studies on the Guduchi Satva show that the yield of the Satva is very less. A lot of pharmaceutical and analytical research work is found regarding Guduchi Satva. But in all above studies, only the conventional method is found adopted while preparing the Guduchi Satva. Use of advanced technology is not found. Use of Multi mill for the preparation of Guduchi Satva can be helpful in the in-process standardization of the Guduchi satva.

\section{Acknowledgments}

None.

\section{Conflicts of interest}

Author declares there are no conflicts of interest.

\section{Funding}

None.

\section{References}

1. Mishra B, Vaishya R. Bhavprakash Nighantu of Bhavmishra. $10^{\text {th }}$ edn. India, Varanasi: Chaukhamba Sanskrit Sansthan; 2002. p.271.

2. Lakshmipati Shastri VS. Yog Ratnakar with Vidyotini Tika. $8^{\text {th }}$ edn. Varanasi: Chaukhamba Sanskrit Sansthan; 2000. p. 382. 
3. SS Vaidya, VA Dole. Bhaishajya Kalpana Pratyakshik. Pune, India: Profishant Publishing House; 2013. p. 177.

4. Rao EV, Rao MV. Studies on the polysaccharide preparation (Guduchi Satva) derived from Tinospora cordifolia. Indian J Pharm Sci. 1981;43:1036.

5. Salunke P, Pimpalgaonkar PB. A comparative study of Guduchi Satva and Guduchi Ghana, MD dissertation, RA Podar College Mumbai, India. 1997.
6. Sharma R, Harisha CR, Galib R, et al.Quantitative estimation of Satva extracted from different stem sizes of Guduchi (Tinospora cordofolia (Willd.) Miers). J Pharm Sci Innov. 2012;1(1):38-40.

7. Rohit Sharma, Hetal Amin, Prajapati PK. Physico-chemical evaluation of Satva extracted from male and female plants of Guduchi (Tinospora cordifolia (Willd.) Miers). J Ayu Herb Med. 2015;1(1):13-16. 